\title{
Fever after acute myocardial infarction in patients treated with intravenous timolol or placebo
}

\author{
CECILIE RISØE, OLE J KIRKEBY, PER GRØTTUM, MAGNUS SEDERHOLM, \\ JOHN K KJEKSHUS
}

From the Department of Medicine, Baerum Hospital, Baerum, Norway

SUMMARY Body temperature was studied in 65 patients admitted to hospital within four hours of $\rightarrow$ the onset of symptoms of acute myocardial infarction. Thirty three patients had been randomlyi assigned to intravenous timolol treatment and 32 to placebo treatment. Infarct evolution waso assessed by continuous vectorcardiography and creatine kinase release. Maximum and mean temperatures during the first eight days were significantly lower in the timolol group, who were discharged from hospital one day earlier. Eight patients in the placebo group had temperatures of $>39^{\circ}$ compared with one in the timolol group. Both the mean temperature and the maximum temperature correlated significantly with indices of infarct size and ischaemic area as estimated by $\vec{\oplus}$ cumulative creatine kinase release, QRS vector difference, and ST vector magnitude. The results were consistent with the view that reduction of infarct size may partly explain the reduced pyrexial response after timolol treatment. Other mechanisms are probably also involved in larger infarcts. Because high fever has detrimental haemodynamic effects in acute myocardial infarction, reduction of this response may be beneficial. The results support the early use of $\beta$ adrenoceptor blockade in acute myocardial infarction.

Fever during acute myocardial infarction is a common finding. Body temperature rises on average more than $1^{\circ} \mathrm{C}$. $^{1}$ The effect of raised temperatures during infarct evolution has not attracted much attention but may, nevertheless, be clinically important. Fever increases heart rate, cardiac work load, metabolic rate, and overall oxygen consumption. A strong pyrexial response to acute myocardial infarction might therefore be deleterious to the jeopardised myocardium.

In a preliminary study we suggested that treatment with the $\beta$ adrenoceptor blocker timolol reduces the pyrexial response to acute myocardial infarction. ${ }^{1}$ We have confirmed this finding in the present prospective, randomised, double blind, placebo controlled, multicentre study in which timolol or placebo was given intravenously within five hours of the onset of suspected myocardial infarction. ${ }^{2}$ Because the study was designed to evaluate the effect of timolol treatment on infarct size we

Requests for reprints to Dr Cecilie Risøe, Department of Medicine, Baerum Hospital, 1316 Baerum Sykehus, Norway.

Accepted for publication 15 July 1986 also examined the relation between the increase in body temperature and vectorcardiographic and? enzymatic indices of the ischaemic injury.

\section{Patients and methods}

Patients of either sex admitted to hospital within four hours of the appearance of symptoms of a first myocardial infarction were considered for inclusion ${ }_{\circ}$ in the study. Exclusion criteria were: bradycardia of $<50$ beats/min, hypotension (systolic blood pres- $\frac{\mathrm{T}}{\mathrm{O}}$ sure $<100 \mathrm{~mm} \mathrm{Hg}$ ), rales more than $10 \mathrm{~cm}$ above the diaphragm, bronchial obstruction, atrioventricularo block of any degree, QRS duration $>0.11$ second, $N$ and concurrent treatment with other cardioactive drugs. The study included 144 patients in nine ${ }_{-}^{\omega}$ hospitals who were randomly assigned within each centre to double blind treatment with timolol male- $-\frac{\tau}{\Phi}$ ate, given intravenously as two bolus injections of $1 \mathrm{mg}$, or to an equal volume of saline, followed by a constant infusion of $0.6 \mathrm{mg}$ timolol per hour orö matching placebo over 24 hours. Oral treatment (timolol $10 \mathrm{mg}$ twice a day or matching placebo) was given for the remainder of the hospital stay. 
Complete temperature charts were available from four of the participating hospitals (Danderyd, Sweden; Haraldsplass, Rogaland, and Baerum; Norway). Temperatures in all hospitals were measured rectally twice a day ( 8 am and $4 \mathrm{pm}$ ) with standard clinical mercury thermometers. The mean temperature was the average of all temperatures measured (morning and afternoon) during the first eight days. The first temperature value obtained after admission was regarded as the reference value. Patients on antipyretic drugs were excluded from the analyses in this study.

Blood samples for creatine kinase estimation were obtained on admission and at two and four hours and then every four hours for the first $\mathbf{4 8}$ hours and thereafter every six hours for up to $\mathbf{7 2}$ hours. Creatine kinase was enzymatically assayed with the Merck creatine kinase NAC (N-acetyl-cysteine) kit. ${ }^{3}$ The cumulative release of the enzyme was measured according to the method developed by Shell et al using an individual decay constant. ${ }^{4}$ The creatine kinase release curve was visually inspected without knowledge of the treatment group and at least five points on the downslope were identified for the calculation of the decay constant. In cases with a non-exponential downslope or evidence of repeated enzyme release a standard decay constant of 0.0576 per hour was used. ${ }^{5}$ The maximum creatine kinase concentration was defined as the highest value obtained from the cumulative enzyme release curve.

Continuous recording of the Frank orthogonal vectorcardiographic leads was performed for 24 hours on analogue tape and analysed off line without knowledge of the treatment regimen. ST vector magnitude and QRS vector difference were calculated. ${ }^{2}$ The first value obtained after admission was regarded as the reference value.

We used the $t$ test, analysis of variance, $\chi^{2}$ test, and Pearson's correlation coefficient to analyse the results.

\section{Results}

A total of 76 patients entered the trial from the four hospitals; 40 were randomly assigned to timolol and 36 to placebo. Eleven patients regularly receiving antipyretic drugs were excluded from the temperature study. This left 33 patients in the timolol group (mean (SD) age $65(12)$ years) and 32 patients in the placebo group (mean (SD) age $63(11)$ ). There were 26 men and seven women in the timolol group and 29 men and three women in the placebo group. Three patients in the timolol group and two patients in the placebo group received antibiotics during the early course. The mean body weights in the two groups were similar: $75.3 \mathrm{~kg}$ (timolol) and $75.6 \mathrm{~kg}$

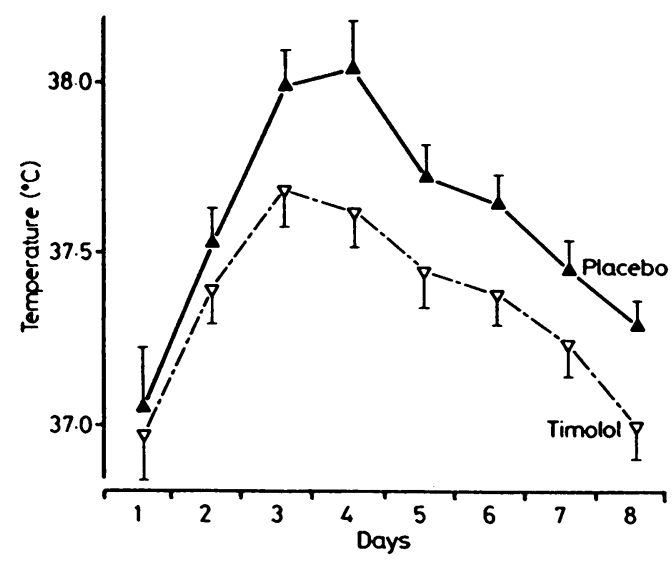

Fig 1 Mean morning temperature (SEM) after acute myocardial infarction.

(placebo).

Figure 1 shows the course of the morning temperatures in the timolol and the placebo groups. Temperature rose higher in the placebo group and the fever lasted for on average a day longer than in the timolol group. Morning temperatures remained above $37.3^{\circ} \mathrm{C}$ for 4.5 days in the timolol group compared with 5.5 days in the placebo group. The difference in temperature was greatest on day 3 ( $p<$ $0.05)$ and day $4(\mathrm{p}<0.025)$ after the infarction. The curve for evening temperatures lay approximately $0.3^{\circ} \mathrm{C}$ above the morning temperatures in both groups and the febrile period was one day shorter for timolol treated patients (afternoon temperatures above $37 \cdot 7^{\circ} \mathrm{C}$ for four days compared with five days in placebo treated patients). The maximum temperatures reached during the course of acute myocardial infarction were significantly lower in the timolol group than in the placebo group ( $p<0.05$ ). The mean temperature during the first eight days was significantly lower in the timolol group ( $p<$ 0.01 ). Exclusion of patients treated with antibiotics did not alter the statistically significant differences between the groups. In the timolol group 10 patients had fever $>38.5^{\circ} \mathrm{C}$ during the first eight days; in the placebo group 19 patients had fever above this level ( $p<0.025)$. Only one patient in the timolol group had fever higher than $39^{\circ} \mathrm{C}$, whereas in eight patients in the placebo group this temperature was attained at some time during the first eight days ( $p$ $<0.01$ ).

The mean temperature during the first eight days and the maximal temperature reached were significantly correlated with infarct size and ischaemic area as estimated by cumulative creatine kinase release, maximum QRS vector difference, 
Table Pearson's correlation coefficients between body temperature and cumulative creatine kinase release, $Q R S$ vector difference, and ST vector magnitude in patients on timolol or placebo

\begin{tabular}{|c|c|c|c|}
\hline & $\begin{array}{l}\text { Cumulative creatine kinase } \\
\text { release }\end{array}$ & $Q R S$ vector difference & $S T$ vector magnitude \\
\hline $\begin{array}{l}\text { Mean temperature: } \\
\text { Timolol group } \\
\text { Placebo group } \\
\text { Both }\end{array}$ & $\begin{array}{l}0 \cdot 20 \\
0.50^{\star \star \star} \\
0.37^{\star \star \star}\end{array}$ & $\begin{array}{l}0 \cdot 37^{\star} \\
0 \cdot 49^{\star \star \star} \\
0 \cdot 49^{\star \star \star \star}\end{array}$ & $\begin{array}{l}0 \cdot 30 \\
0 \cdot 48^{\star \star \star} \\
0 \cdot 42^{\star \star \star \star}\end{array}$ \\
\hline $\begin{array}{l}\text { Maximum temperature: } \\
\text { Timolol group } \\
\text { Placebo group } \\
\text { Both }\end{array}$ & $\begin{array}{l}0 \cdot 10 \\
0 \cdot 47^{\star \star \star} \\
0 \cdot 37^{\star \star \star}\end{array}$ & $\begin{array}{l}0.38 \\
0.37^{\star} \\
0 \cdot 41^{\star \star}\end{array}$ & $\begin{array}{l}0.20 \\
0.37^{\star} \\
0.33^{\star \star \star}\end{array}$ \\
\hline
\end{tabular}

and initial ST vector magnitude (table). The correlation was highly significant for the total study groups of 65 patients and for the placebo group but not for the timolol group.

Figure 2 shows the mean temperature for patients with a maximum cumulative creatine kinase release $<1000 \mathrm{U} / 1,1001$ to $2000 \mathrm{U} / 1$, and $>2000 \mathrm{U} / \mathrm{l}$. Timolol reduced the mean temperature in patients with myocardial infarctions associated with a maximum cumulative creatinine kinase release of $>1000 \mathrm{U} / 1$ ( $p$ $<0.01$ ).

Timolol treated patients were discharged from hospital on average one day before patients on placebo (median hospital stay 11 days in timolol group (range 7-32), 12 days in placebo group (range 8-28)).

\section{Discussion}

The present study shows that the early adminis-

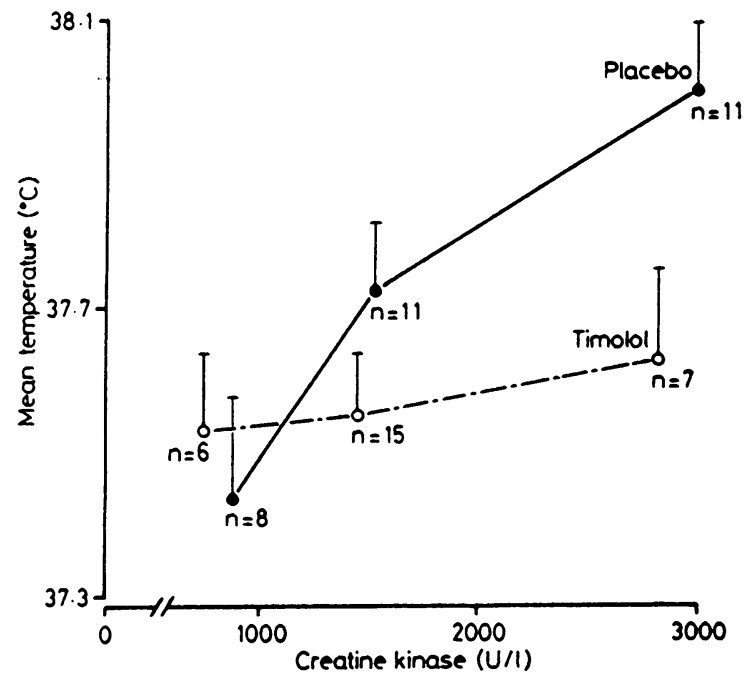

Fig 2 Mean temperature (SEM) in patients with a maximal cumulative creatine kinase release (CK) below $1000 \mathrm{U} / l, 1001$ to $2000 \mathrm{U} / \mathrm{l}$, and above $2000 \mathrm{U} / \mathrm{l}$. tration of timolol to patients with acute myocardiak infarction significantly reduces the pyrexial response to the condition. The fever was reduced both in duration and magnitude and fewer patients on tim olol treatment reached high temperatures.

The original study was not designed to estimat $\vec{\varepsilon}$ differences in temperature between the groups. Temperature is, however, one of the most precis and frequently performed clinical examinations or patients in hospital. The data are thus complete and a prospective trial specifically designed to asses: temperature differences in acute myocardiat infarction would only be slightly more accurate.

The mechanism of fever in sterile inflammation of trauma such as an acute myocardial infarction is unclear. ${ }^{6}$ Fever is generated by an endogenous mediator shown to resemble or be identical to inter leukin 1. Interleukin 1 causes fever by altering the set point for the thermostat in the hypothalamus. It is produced by mononuclear phagocytes when the are challenged with viral or bacterial products. Non-infectious diseases such as acute myocardian infarction probably also induce interleukin 1 pro duction as other effects of interleukin 1 (such as reduction of serum iron, induction of acute phase. proteins, and granulocytosis) have been shown te occur in the early phase of the disease. ${ }^{8}$ The mag nitude of fever, as estimated by mean temperature and maximum temperature during the first eight days, correlated significantly with cumulative cre atine kinase release, $Q R S$ vector difference, and STO vector magnitude. This suggests that the fever response during acute myocardial infarction is ini tiated by necrotic myocardium. It is possible thaw infarcted myocardium induces production of inter? leukin 1 and that the size and duration of the proces? of infarction determine the amount of interleukin produced.

Beta adrenoceptor blockade may affect the febrile response after acute myocardial infarction in severat ways. As outlined above, infarcted myocardial tissue is a possible stimulus for interleukin 1 production? Our results suggest that the size of the infarction 
correlates with the pyrexial response. Thus reduction of infarct size may, at least in part, explain the reduced fever response after early timolol treatment. For larger infarctions timolol treatment probably reduces the temperature response through one or more additional mechanisms (fig 2).

The effect of the $\beta$ adrenoceptors in the temperature regulating centre have not been established. It - is possible, at least theoretically, that $\beta$ blockers may affect temperature regulation through these receptors. ${ }^{9}$ Beta adrenoceptors are certainly involved in the peripheral regulation of body temperature. Beta adrenoceptor blockade induces vasoconstriction, ${ }^{10}$ which tends to increase body temperature. Reduction of shivering, non-shivering thermogenesis, and metabolic rate, however, lowers body temperature. ${ }^{10}$ Our results suggest that the net effect of $\beta$ adrenoceptor blockage is a reduced pyrexial response.

Fever may impair cardiovascular function. Tachycardia is commonly observed and heart rate is increased by approximately $30 \%$ from the basal level at a body temperature of $38.5^{\circ} \mathrm{C} .{ }^{11}$ This increase in heart rate increases myocardial oxygen requirements and might predispose to extension of the infarct and to arrhythmias. Shortening of diastolic perfusion time when heart rate is increased reduces blood flow to the myocardium. Moderate fever reduces stroke volume and cardiac output in patients with a normal myocardium, and subclinical impairment of cardiac function might thus be induced by various febrile conditions. ${ }^{11-13}$ Metabolic rate is increased during fever and it has been shown that there is a $13-15 \%$ increase in oxygen consumption for every ${ }^{\circ} \mathrm{C}$ increase in body temperature. $^{14}$ In acute myocardial infarction an increase of metabolic rate and oxygen consumption increases the risk of cardiac failure. Thus there are several factors to suggest that a strong pyrexial response is detrimental to patients with an acute myocardial infarction.

On average timolol treated patients spent one day less in hospital than placebo treated patients. A similar observation was made in patients with acute myocardial infarction treated with metoprolol. ${ }^{15}$ Although the severity of the infarction may be an important determinant for the length of hospital stay, an early return to normal body temperature is usually accompanied by early mobilisation of the patient. Hence the fever reducing effect of timolol might lead to earlier discharge from hospital.

Our results show that timolol reduces the fever after acute myocardial infarction. We believe that this has beneficial haemodynamic effects in these patients and that our results support the early use of $\beta$ adrenoceptor blockade in acute myocardial infarction.

\section{References}

1 Risøe C, Kirkeby OJ. Reduction of the pyrexial response to acute myocardial infarction by betaadrenoceptor blockade. Acta Med Scand 1986; 219:271-4.

2 The International Collaborative Study group. Reduction of infarct size with the early use of timolol in acute myocardial infarction. $N$ Engl $\mathcal{F}$ Med 1984;310:9-15.

3 The Committee on Enzymes of The Scandinavian Society for Clinical Chemistry and Clinical Physiology. Recommended method for the determination of creatine kinase in blood. Scand $\mathcal{f}$ Clin Lab Invest 1976;36:711-23.

4 Shell WE, Kjekshus JK, Sobel BE. Quantitative assessment of the extent of myocardial infarction in the conscious dog by means of analysis of serial changes in serum creatine phosphokinase activity. $\boldsymbol{f}$ Clin Invest 1971;50:2614-25.

5 Sederholm M, Grøttum P, Erhardt L, Kjekshus JK. Quantitative assessment of myocardial ischaemia and necrosis by continuous vectorcardiography and measurement of creatine kinase release in patients. Circulation 1983;68:1006-12.

6 Atkins E. Fever-new perspectives on an old phenomenon. $N$ Engl f Med 1983;308:958-60.

7 Baracos V, Rodeman HP, Dinarello CA, Goldberg AI. Stimulation of muscle protein degradation and prostaglandin E2 release by leucocytic pyrogen (Interleukin 1). N Engl f Med 1983;308:553-8.

8 Fitzsimons EJ, Kaplan K. Rapid drop in serum iron concentration in myocardial infarction: Am $\mathcal{f}$ Clin Pathol 1980;73:552-5.

9 Kasiazek A, Klemok Z. The central action of betaadrenergic receptor blocking drugs. Pol $\mathcal{F}$ Pharmacol Pharm 1974;26:287-95.

10 Welle SL, Thompson DA, Campbell RG. Betaadrenergic blockade inhibits thermogenesis and lipolysis during glucoprivation in humans. $A m \boldsymbol{J}$ Physiol 1982;243:R379-82.

11 Abdullah AK, Goel JK, Siddiqui MA. Systolic time intervals in febrile states. Fpn Heart $\mathcal{F} 1981$; 22:739-45.

12 Friman G, Wright JE, Ilback NG, et al. Does fever or myalgia indicate reduced physical performance capacity in viral infections? Acta Med Scand 1985;217:353-61.

13 Friman G. Effects of acute infectious diseases on circulatory function. Acta Med Scand 1976;200 (suppl 592):1-62.

14 duBois EF. The basal metabolism in fever. $\mathcal{F} A M A$ 1921;77:352-5.

15 Herlitz J, Hartford M, Pennert K, et al. Göteborg metoprolol trial: clinical observations. $A m \mathcal{F}$ Cardiol 1984;53:37D-45D. 